\title{
Characteristics of Hard Coatings on AZ61 Magnesium Alloys
}

\author{
Tomasz Tański* \\ Silesian University of Technology, Institute of Engineering Materials and Biomaterials, Poland
}

Gradient/monolithic coatings (Ti/TiCN/CrN, Ti/TiCN/TiAIN, Ti/DLC/DLC) were deposited onto magnesium alloy (Mg-Al-Zn) substrate by Cathodic Arc Evaporation method and Plasma Assisted Chemical Vapor Deposition method. A thin metallic layer (Ti) was deposited prior to deposition of gradient coatings to improve adhesion. The microstructure wear resistance and adhesion of the investigated coatings were studied. SEM micrographs showed that the deposited coatings are characterized by compact structure without delamination or defects and they closely adhere to each other. The critical load LC lies within the range of 8-17 N, depending on the coating type. The DLC coatings demonstrate the highest wear resistance. The good properties of the PVD gradient coatings make them suitable in various industrial applications.

Keywords: Magnesium alloys, hard coatings, physical vapour deposition (PVD), plasma assisted chemical vapor deposition (PACVD), structure, properties

\section{INTRODUCTION}

Magnesium alloys have excellent physical and mechanical properties for a number of applications. In particular its high strength, weight ratio makes it an ideal metal for automotive and aerospace applications, where weight reduction is of significant concern. Magnesium is the $6^{\text {th }}$ most abundant element on Earth making up approximately $2.09 \%$ by mass of the Earth's crust. Magnesium alloys, in addition to a low density of $\left(1.7 \mathrm{~g} / \mathrm{cm}^{3}\right)$, also have some other advantages like good ductility, noise and vibration dampening characteristics and excellent castability, high stability of the size and shape, low shrinkage, as well recyclability, which makes it possible to achieve recycled alloys with quality and properties very close to primary cast alloys, which enables the application of these materials instead of new manufactured $\mathrm{Mg}$ alloy for constructions of less importance [1] to [6]. Due to limited fossil fuel stores and environmental problems associated with fuel emission products, there is a push in the automotive industry to make cars lighter in order to decrease fuel consumption. The use of magnesium alloys can significantly decrease the weight of automobiles without sacrificing structural strength [7] to [10].

For the reason of surface protection of the applied engineering materials, including the discussed magnesium alloys for improving their surface properties, often diverse kinds and types of surface engineering techniques are used, including technologies for coating of surface layers during PVD processes.

The progress in the area of manufacturing and extending the life expectancy of the constructional elements and tools, used in various domains of life, is taking place mostly owing to the more and more common employment of the thin coatings deposition, made from hard, wear resistant ceramic materials. A big selection of coatings available actually and their deposition technologies are the effects of the recent growing demand for the contemporary modification methods and materials' surface protection. Currently, the CVD (Chemical Vapour Deposition), and PVD (Physical Vapour Deposition) methods play an important role in the industrial practice among many techniques improving the life of materials [11] to [17]. The PVD techniques are currently commonly used for improving the mechanical and functional properties of a wide range of engineering materials [18] to [20]. Thanks to the relatively low PVD process temperature, other than the CVD processes there is no risk of losing the properties acquired during the heat treatment of the coated materials.

On the leading annual World Congresses on coatings, including ThinFilms2012 in Singapore, among the presented articles several of them concern surface layers with a gradient-, composite-, or nanocomposites structure, obtained using the PVD and CVD technique, replacing older generation coatings, such as simple - monolayer, alloying/multicomponent or multiphase layers, as well as coated on magnesium and aluminium alloys. Progress in the field of coating production obtained by the physical vapour deposition process allows it to achieve hybrid functional coatings - gradient and multi-component, which reveals high mechanical and functional properties. Coatings of this structure have a low friction coefficient (selflubricating coatings) in many working environments, while maintaining high hardness and increased resistance to external factors. The key issue seems to be also to ensure a simultaneous development of both manufacturing technology and treatment of constructional light materials, in particular of magnesium alloys, as well as technology for modelling and protection of the surface, which will finally allow 
to preserve the balance between the modern substrate materials and the new generation coating.

The aim of this innovative work was to obtain best possible hybrid coatings, consisting of - a gradient transition layer, with a continuous change of one or more components reaching from the substrate to the surface top - as well as an outer coating using the Cathodic Arc Evaporation process and Plasma Assisted Chemical Vapor Deposition process on the surface of the cast AZ61 magnesium alloys to increase properties and the low stiffness of the substrate material. This article focuses on the properties and structure analysis in order to evaluate the quality of the obtained coating.

\section{EXPERIMENTAL PROCEDURE}

The material used for investigation was the magnesium alloy AZ61. The chemical composition of the investigated alloy is presented in Table 1. The CAE method was employed in own research for depositing the hard, wear resistant PVD coatings (TiCN/CrN, TiCN/TiAlN). The coatings deposition process was carried out in the arc-vacuum chamber based on the arc evaporation method, the so called Cathodic Arc Evaporation in an $\mathrm{Ar}, \mathrm{N}_{2}$ and $\mathrm{C}_{2} \mathrm{H}_{2}$ atmosphere. Cathodes containing pure metals $(\mathrm{Cr}, \mathrm{Ti})$ and the TiAl (50:50 at. \%) alloy were used for deposition of the coatings. The diameter of the used cathodes was $65 \mathrm{~mm}$. After pumping the chamber the base pressure was $5 \times 10^{-3} \mathrm{~Pa}$ (Table 2). The temperature was controlled by thermocouples. Then, the substrates were cleaned by argon ion at the pressure $2 \mathrm{~Pa}$ for 20 min. To improve the adhesion of coatings, a transition $\mathrm{Cr}$ or $\mathrm{Ti}$ interlayer was deposited. The working pressure during the deposition process was 2 to $4 \mathrm{~Pa}$ depending of the coatings type. The distance between each of the cathodes and the deposited substrates was $120 \mathrm{~mm}$. Moreover, the DLC coating were deposited using acetylene $\left(\mathrm{C}_{2} \mathrm{H}_{2}\right)$ as precursor and was produced by PACVD process. The substrates were cleaned by argon ion at the pressure $2 \mathrm{~Pa}$ for $20 \mathrm{~min}$ in bias voltage $800 / 200 \mathrm{~V}$. To improve the adhesion of coatings, a transition Ti interlayer was deposited. Conditions of coating deposition are presented in Table 2.

The examinations of thin foils microstructure and phase identification were made on the JEOL 3010CX transmission electron microscope (TEM), at the accelerating voltage of $300 \mathrm{kV}$ using selected area diffraction method (SAD) for phase investigations. The diffraction patterns from the TEM were solved using a special computer program "Eldyf" software supplied by the Institute of Material Science o the
University of Silesia. TEM specimens were prepared by cutting thin plates from the material. The specimens were ground down to foils with a maximum thickness of $80 \mu \mathrm{m}$ before $3 \mathrm{~mm}$ diameter discs were punched from the specimens. The disks were further thinned by ion milling method with the Precision Ion Polishing System (PIPS ${ }^{\mathrm{TM}}$ ), used the ion milling device model 691 supplied by Gatan until one or more holes appeared. The ion milling was done with argon ions, accelerated by a voltage of $15 \mathrm{kV}$.

Table 1. Chemical composition of the investigated magnesium alloys

\begin{tabular}{cccccccc}
\hline Type of & \multicolumn{6}{c}{ Mass concentration of the elements [\%] } \\
\cline { 2 - 8 } material & $\mathrm{Al}$ & $\mathrm{Zn}$ & $\mathrm{Mn}$ & $\mathrm{Si}$ & $\mathrm{Fe}$ & $\mathrm{Mg}$ & Rest \\
\hline AZ61 & 5.92 & 0.49 & 0.15 & 0.04 & 0.01 & 93.33 & 0.06 \\
\hline
\end{tabular}

Table 2. Deposition parameters of the investigated coatings

\begin{tabular}{|c|c|c|c|}
\hline \multirow{3}{*}{$\begin{array}{l}\text { Process } \\
\text { parameters }\end{array}$} & \multicolumn{3}{|c|}{ Coating type } \\
\hline & \multicolumn{2}{|c|}{$\begin{array}{l}\text { PVD } \\
\text { process }\end{array}$} & \multirow{2}{*}{$\begin{array}{c}\text { PACVD } \\
\text { process } \\
\text { Ti/DLC/DLC }\end{array}$} \\
\hline & $\begin{array}{c}\mathrm{Ti} / \mathrm{Ti}(\mathrm{C}, \mathrm{N})- \\
\text { gradient/(Ti,Al)N }\end{array}$ & $\begin{array}{c}\mathrm{Ti} / \mathrm{Ti}(\mathrm{C}, \mathrm{N})- \\
\text { gradient/CrN }\end{array}$ & \\
\hline $\begin{array}{l}\text { Base pressure } \\
{[\mathrm{Pa}]}\end{array}$ & $5 \times 10^{-3}$ & $5 \times 10^{-3}$ & $1 \times 10^{-3}$ \\
\hline $\begin{array}{l}\text { Working pressure } \\
{[\mathrm{Pa}]}\end{array}$ & $\begin{array}{c}9.0 \times 10^{-1 /} / \\
1.1 \text { to } 1.9 / 2.8\end{array}$ & $\begin{array}{c}9.0 \times 10^{-1} / \\
1.1 \text { to } 1.9 / 2.2\end{array}$ & 2 \\
\hline \multirow{3}{*}{$\begin{array}{l}\text { Argon flow rate } \\
\text { [sccm (standard } \\
\text { cubic centimeter } \\
\text { per minute)] }\end{array}$} & $80^{\star}$ & $80^{*}$ & $80^{*}$ \\
\hline & $10^{* \star}$ & $10^{* \star}$ & - \\
\hline & $10^{\star \star \star}$ & $10^{\star \star \star}$ & - \\
\hline \multirow{2}{*}{$\begin{array}{l}\text { Nitrogen flow rate } \\
\text { [sccm] }\end{array}$} & $0 \rightarrow 225^{\star \star}$ & $225 \rightarrow 0$ ** & - \\
\hline & $350 * \star \star$ & $250 * \star \star$ & - \\
\hline $\begin{array}{l}\text { Acetylene flow } \\
\text { rate }[\mathrm{sccm}]\end{array}$ & $140 \rightarrow 0^{\star *}$ & $0 \rightarrow 170^{* *}$ & 230 \\
\hline \multirow{3}{*}{$\begin{array}{l}\text { Substrate bias } \\
\text { voltage [V] }\end{array}$} & $70^{\star}$ & $70 *$ & \multirow{3}{*}{500} \\
\hline & $70^{\star \star}$ & $70^{\star \star}$ & \\
\hline & $70 * \star \star$ & 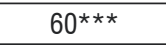 & \\
\hline Target current $[\mathrm{A}]$ & 60 & 60 & - \\
\hline $\begin{array}{l}\text { Process } \\
\text { temperature }\left[{ }^{\circ} \mathrm{C}\right]\end{array}$ & $<150$ & $<150$ & $<180$ \\
\hline \multicolumn{4}{|c|}{$\begin{array}{l}\text { *during metallic layers deposition; } \\
{ }^{\star *} \text { during gradient layers deposition; } \\
{ }^{* *} \text { during ceramic layers deposition. }\end{array}$} \\
\hline
\end{tabular}

Microstructure investigation was performed using scanning electron microscope (SEM) ZEISS Supra 25 with a magnification between 10000 and 35000 times. For microstructure evaluation the Secondary Electrons (SE) detection was used, with the accelerating voltage of 5 to $25 \mathrm{KV}$. For a complex metallographic analysis of the fractures of the investigated samples, the material with the coated layer was initially cut, and before braking cooled down in liquid nitrogen. Qualitative and quantitative chemical composition analysis in 
micro-areas of the investigated coatings was performed using the X-Ray microanalysis (EDS) by mind of the spectrometer EDS LINK ISIS supplied by Oxrord. This device is attached to the electron scanning microscope Zeiss Supra 35. The investigations were performed by an accelerating voltage of $20 \mathrm{kV}$.

Wear resistance investigations were performed using the ball-on-disk method in dry friction conditions in the horizontal settlement of the rotation axis of the disk. As the counterpart there was a tungsten carbide ball with a diameter of $3 \mathrm{~mm}$ used. The tests were performed at room temperature by a defined time using the following test conditions:

- load, Fn-5 N,

- rotation of the disk 200 turns/min,

- wear radius of $2.5 \mathrm{~mm}$,

- shift rate of $-0.05 \mathrm{~m} / \mathrm{s}$.

Tests of the coatings' adhesion to the substrate material were made using the scratch test on the CSEM REVETEST device, by moving the diamond indenter along the examined specimen surface with gradually increasing load. The device registered the friction force, friction coefficient, indenter penetration depth and acoustic emission along the scratch track. The tests were made using the following parameters: load range: 0 to $100 \mathrm{~N}$; load increase rate $(d L / d t): 100$ $\mathrm{N} / \mathrm{min}$; indenter's sliding speed $(d x / d t): 10 \mathrm{~mm} / \mathrm{min}$; acoustic emission detector's sensitivity AE: 1 .

\section{RESULTS AND DISCUSSION}

Results of diffraction method investigations allow to identify the (Ti,Al)N, $\mathrm{CrN}$ and graphit phases occurred in the surface layer (Figs. 4, 6 and 10).

TEM investigation results are presented on Figs. 1 to 10 . For analysed cases in the investigated areas a nanocrystalline microstructure of the surface layer was detected. In Fig. 2 the microstructures of the layer $(\mathrm{Ti}, \mathrm{Al}) \mathrm{N}$ are shown and graphite phases, using the dark field technique the size of the subgrains or crystallites can be determined. Also, a globular compact structure was confirmed as well a high uniformity of the crystallites with a uniform size within the range of 10 to $15 \mathrm{~nm}$. According to the literature and based on own investigations it is possible to conclude that the character (unevenly distributed large clusters of reflections from the coating, forming large systematic groups in the polycrystalline diffraction circles) of the electron diffraction pattern of the coating $\operatorname{Ti}(\mathrm{C}, \mathrm{N}) /$ $\mathrm{CrN}$ shows the occurrence of fine-grained crystallite structure of the size of $\leq 10 \mathrm{~nm}$ (Fig. 5). For phase determination of the structure of the surface layer diffraction pattern analysis of the investigated areas has allowed it to identify the (Ti, Al)N phase (Figs. 3 and 4) as a Cubic phase of the Fm3m (225) space group with the $d$-spacing of $\mathrm{a}=\mathrm{b}=\mathrm{c}=0.424173 \mathrm{~nm}$. For the $\mathrm{Ti} / \mathrm{Ti}(\mathrm{C}, \mathrm{N}) / \mathrm{CrN}$ coated $\mathrm{Mg}$ substrate the $\mathrm{CrN}$ phase as a cubic phase of the $225-\mathrm{Fm} 3 \mathrm{~m}$ space group with the d-spacing of $\mathrm{a}=\mathrm{b}=\mathrm{c}=0.414 \mathrm{~nm}$ (Figs. 5 and 6) was determined.

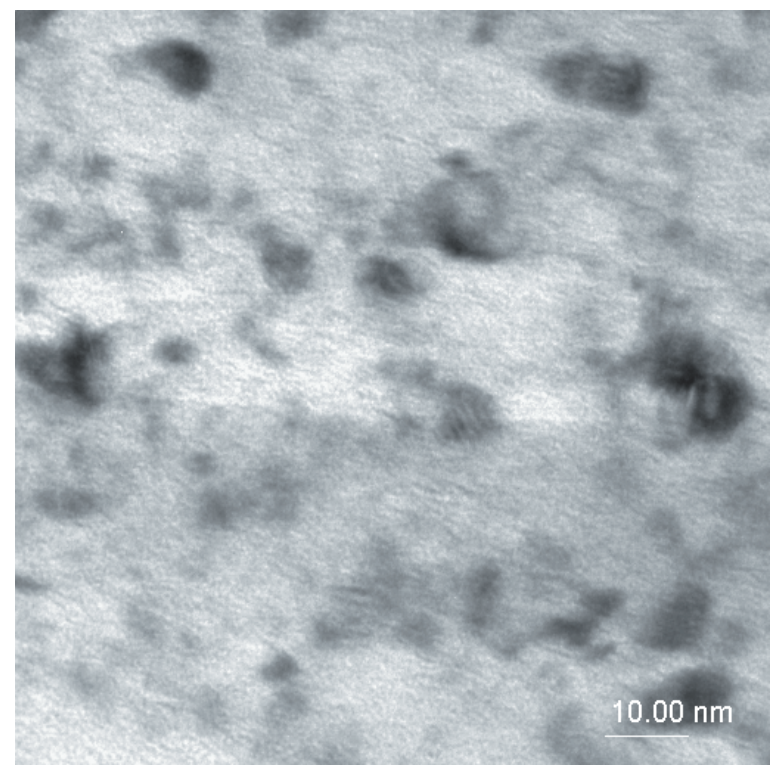

Fig. 1. Microstructure of the (Ti,AI)N surface layer, bright field, TEM

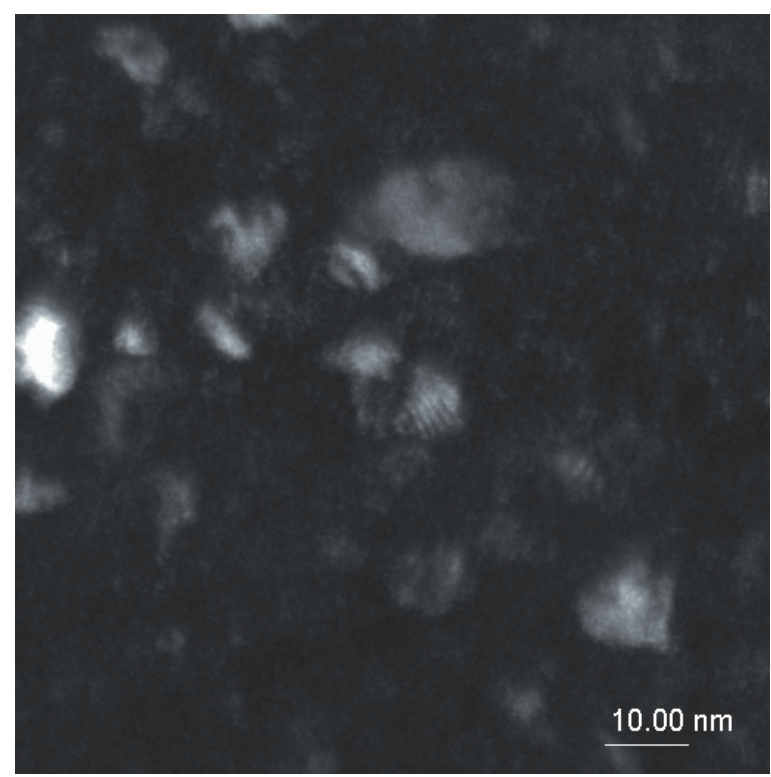

Fig. 2. Microstructure of the (Ti,AI)N surface layer, dark field, TEM

The graphite phase was determined as a hexagonal phase of the 186-P63mc space group with the $\mathrm{d}$-spacing of $\mathrm{a}=\mathrm{b}=0.2, \mathrm{c}=0.679 \mathrm{~nm}$ (Figs. 9 
and 10), identification of the radius of the first circle visible on the obtained diffraction pattern (Fig. 10) allowed unambiguous confirmation of the graphite phase.

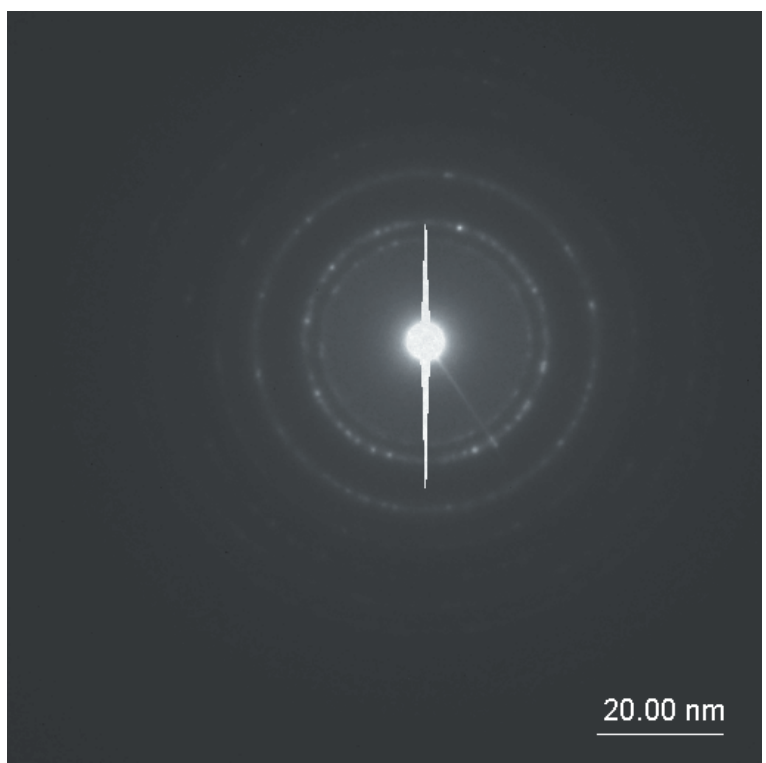

Fig. 3. Diffraction pattern of the polycrystalline surface layer presented in Figs. 1 and 2

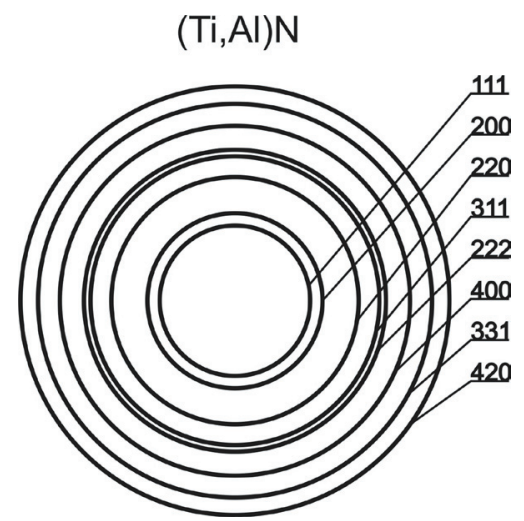

Fig. 4. Solution of the diffraction pattern presented in Fig. 3

As a result of the microstructure investigations on scanning electron microscope it has been found that there are no pores or cracks in the produced coating and any defects and failures occurring spontaneously in this single layer are not of significant importance for the properties of the whole layer (Figs. 11, 13 and 15).

Thickness of the obtained coatings was measured using metallographic observations performed on the scanning electron microscope on sample fractures. Thickness measurements in different locations of the observed fractures have confirmed the uniformity of the coated layers. The thickens of the $\mathrm{Ti} / \mathrm{Ti}(\mathrm{C}, \mathrm{N}) / \mathrm{CrN}$ and $\mathrm{Ti} / \mathrm{Ti}(\mathrm{C}, \mathrm{N}) /(\mathrm{Ti}, \mathrm{Al}) \mathrm{N}$ layers can be determined in the range up to $3.3 \mu \mathrm{m}$, while the carbon layer thickness oscillated between $2.5 \mathrm{~mm}$. Fracture investigations confirm also that the $\mathrm{Ti} / \mathrm{Ti}(\mathrm{C}, \mathrm{N}) / \mathrm{CrN}$ and $\mathrm{Ti} / \mathrm{Ti}(\mathrm{C}, \mathrm{N}) /(\mathrm{Ti}, \mathrm{Al}) \mathrm{N}$ layers has a layered structure with a clearly visible transition zone between the gradient layer and the wear resistant coating achieved using separate metals evaporation sources (Figs. 11 and 13).

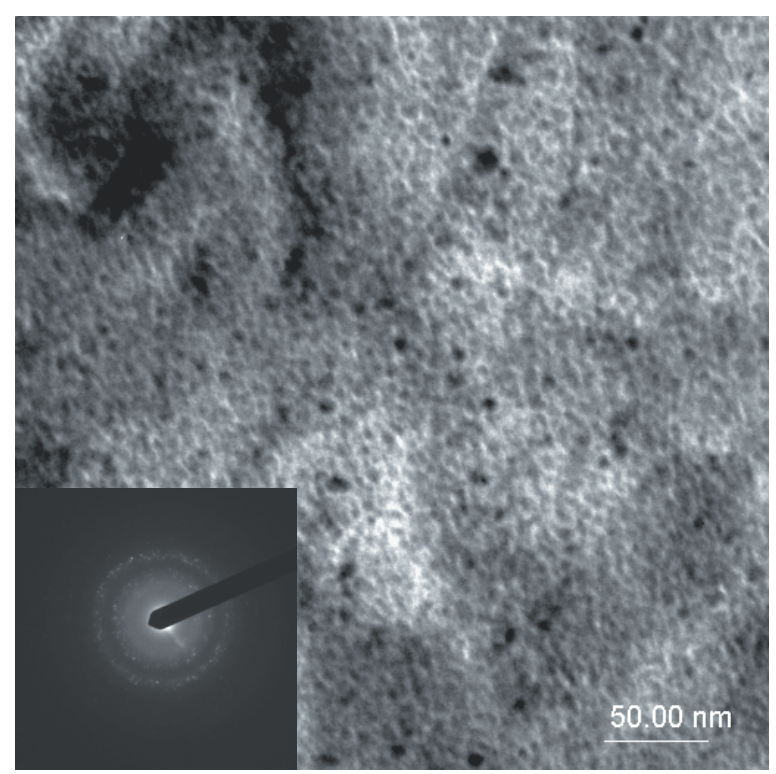

Fig. 5. Microstructure of the CrN surface layer, bright field and diffraction pattern of the polycrystalline surface layer, TEM

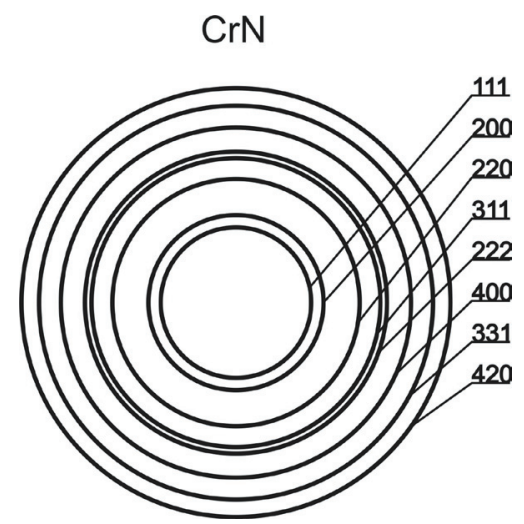

Fig. 6. Solution of the diffraction pattern presented in Fig. 7

Due to the same phase composition of the gradient coatings and the wear resistant coating the characteristic separation between these both coatings in the case of carbon coating could not be identified, however characteristic bright, continuous layer $\mathrm{Ti}$ in area of the sub-shell, which improves the adhesion (Fig. 15) could be identified. The morphology of the 
fracture of the layers is also characterised by a lack of columnar structure. (Figs. 11 to 15 ).

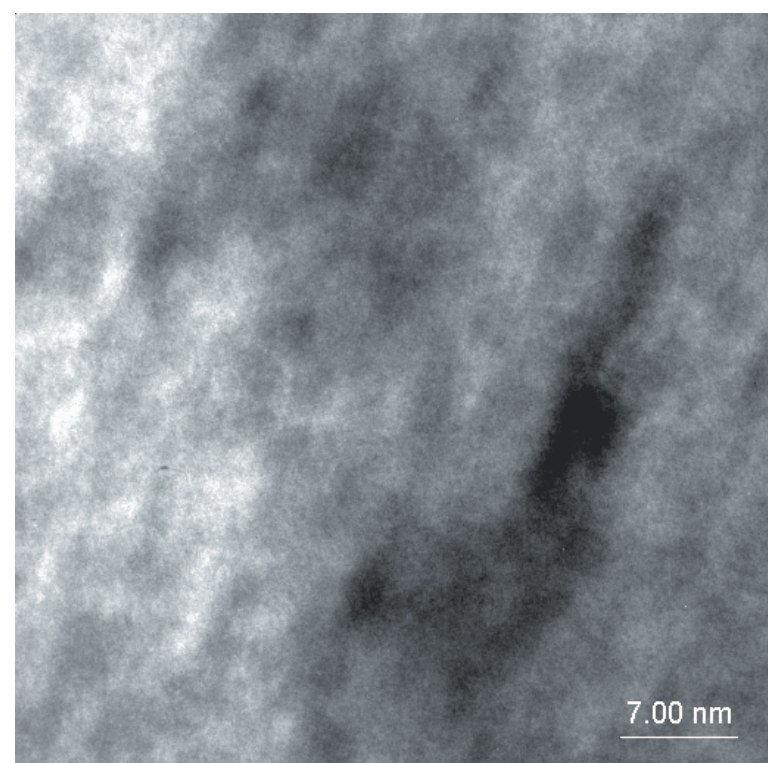

Fig. 7. Microstructure of the DLC surface layer, bright field, TEM

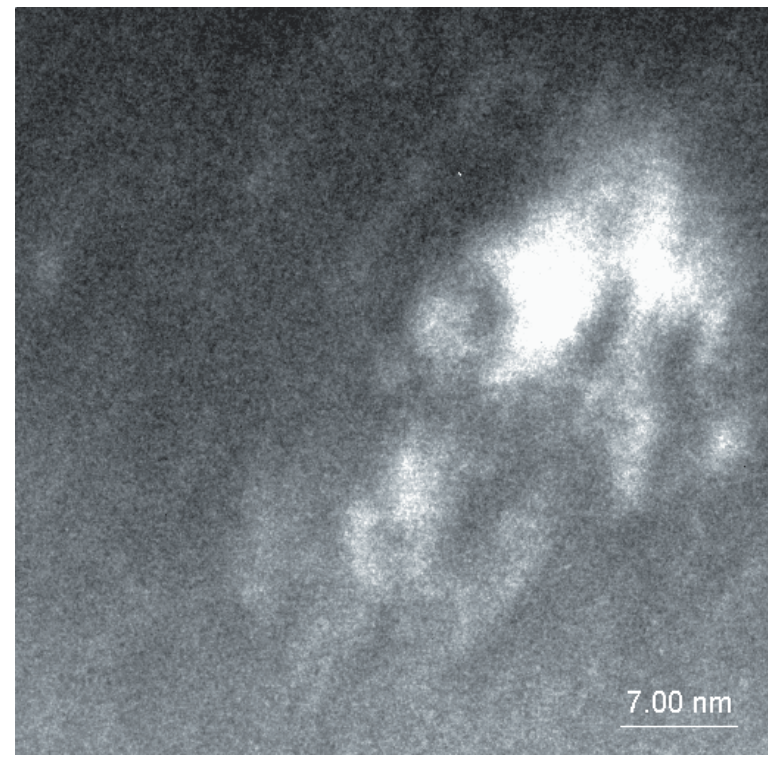

Fig. 8. Microstructure of the DLC surface layer, dark field, TEM

On the basis of the performed observations on scanning electron microscope the coating of the Ti/ DLC/DLC type show an increasing non-homogeneity compared to the $\mathrm{Ti} / \mathrm{Ti}(\mathrm{C}, \mathrm{N}) /(\mathrm{Ti}, \mathrm{Al}) \mathrm{N}$ and $\mathrm{Ti} / \mathrm{Ti}(\mathrm{C}, \mathrm{N}) /$ $\mathrm{CrN}$ coatings which is connected with the presence of numerous droplet-shaped microparticles and should that fore significantly influence on mechanical properties of the achieved coatings (Figs. 12, 14 and 16). The droplets observed in SEM are noticeably different in terms of size and shape (regular and irregular shape, slightly flat). There were probably also some hollows formed when the solidified droplets break off after the PVD process has been completed (Figs. 12 and14). The occurrence of such morphology defects is connected to the nature of the cathodic process of the electric arc evaporation. In case of the Ti/DLC/DLC coating there were identified small amounts of droplets (Fig. 16).

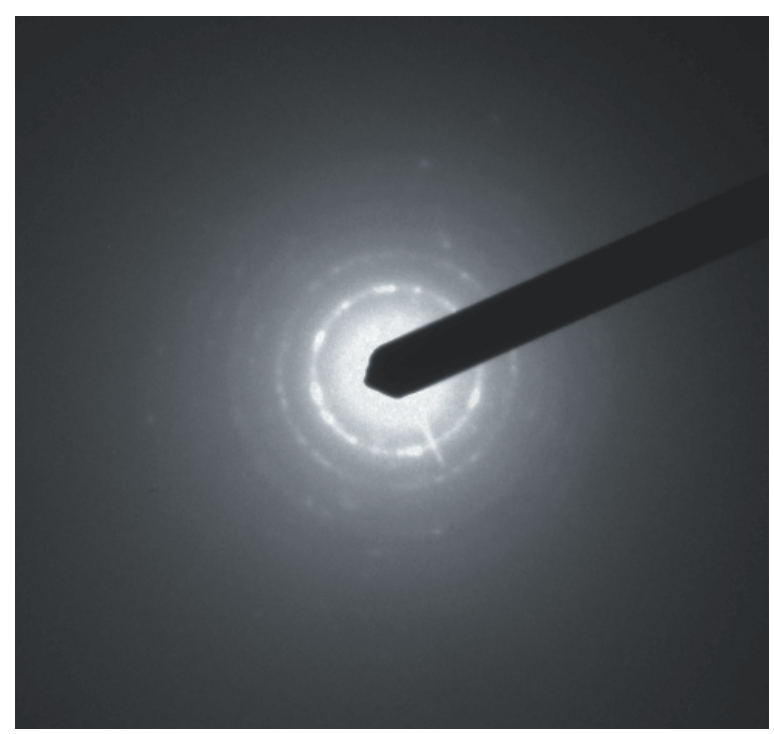

Fig. 9. Diffraction pattern of the surface layer presented in Figs. 1 and 2

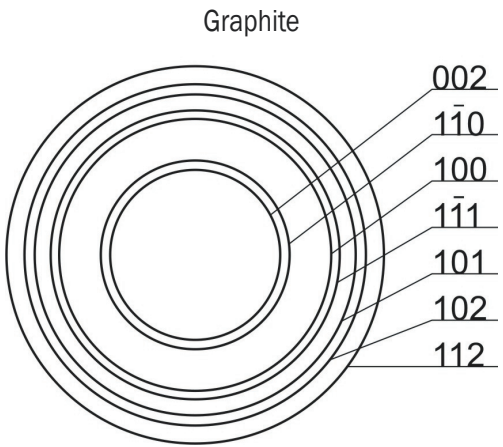

Fig. 10. Solution of the diffraction pattern presented in Fig. 3

As a result obtained by the quantitative X-ray microanalysis using the energy dispersed $\mathrm{X}$-ray EDS spectrometer it the presence of $\mathrm{Mg}, \mathrm{Al}, \mathrm{Zn}, \mathrm{Ti}, \mathrm{Cr}, \mathrm{C}$, $\mathrm{N}$, as major alloying elements of the cast of magnesium alloys as well the obtained coatings (Fig. 17, Table 4) has been Confirmed. As the size of the particular structure elements is mainly lower than the diameter at the incident electron beam the achieved image in the quantitative EDS analysis can be calculated as the average value, which can lead to partially enhanced values for some element concentrations. 


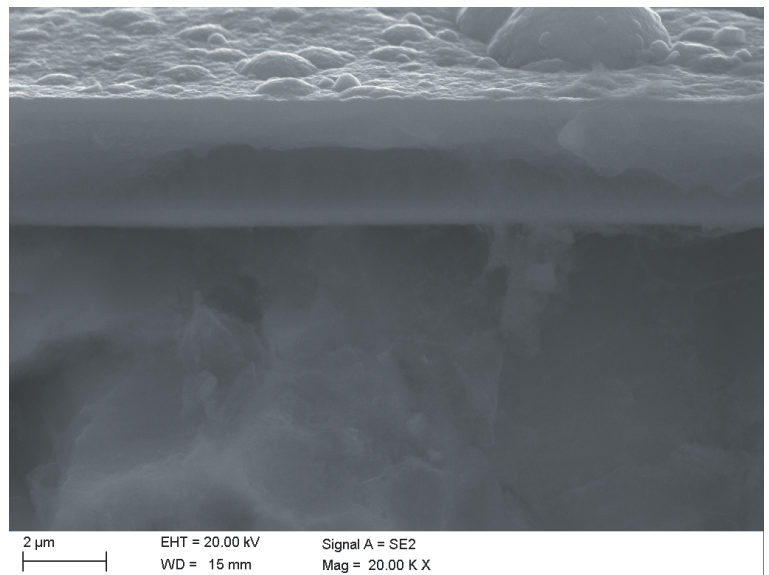

Fig. 11. Cross-section SEM images of the Ti/Ti(C,N)/(Ti,Al)N coating deposited onto the AZ61 substrate

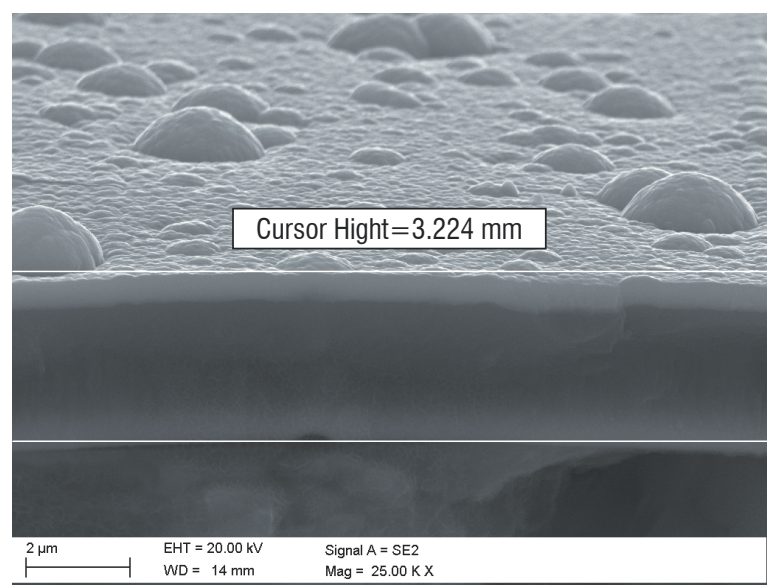

Fig. 13. Cross-section SEM images of the Ti/Ti(C,N)/CrN coating deposited onto the AZ61 substrate

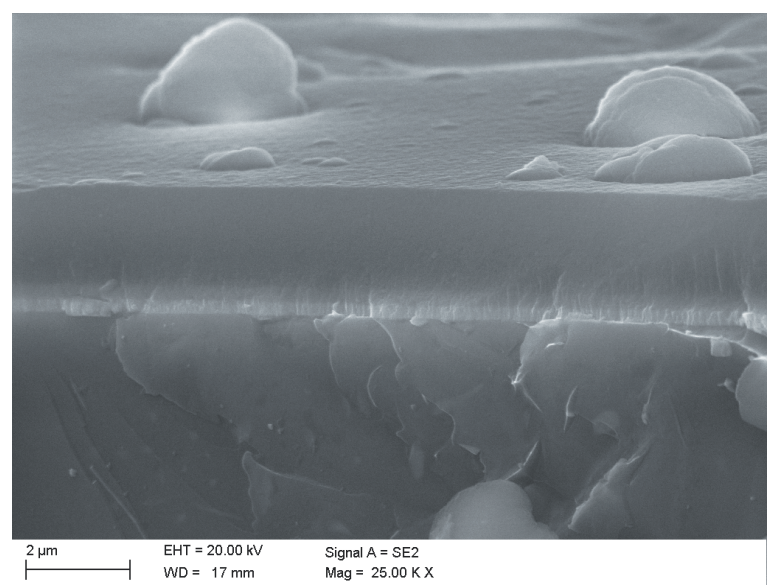

Fig. 15. Cross-section SEM images of the Ti/DLC/DLC coating deposited onto the AZ61 substrate

To determine the tribological properties of the investigated coating deposited on the magnesium

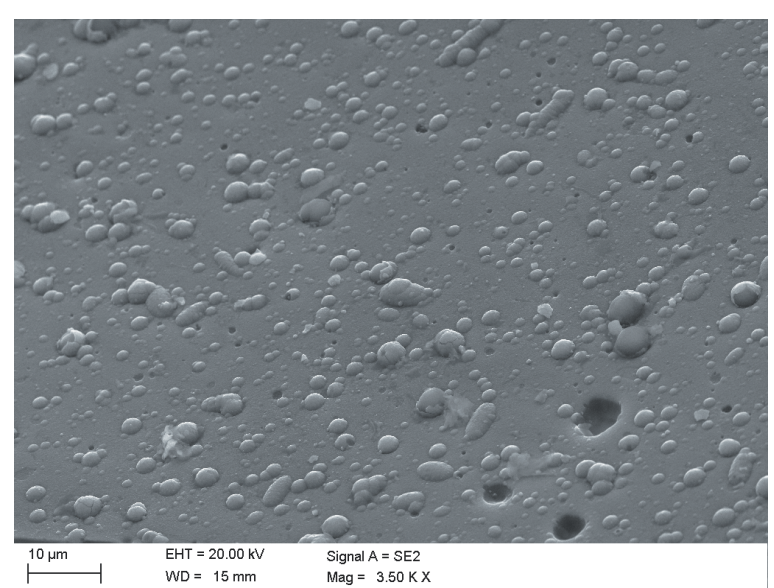

Fig. 12. Surface topography of the Ti/Ti(C,N)/(Ti,Al)N coating deposited onto AZ61 substrate

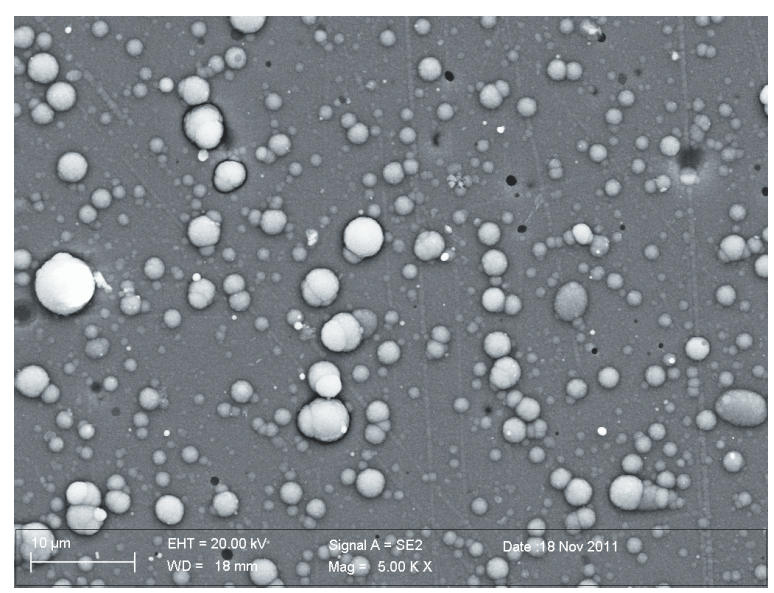

Fig. 14. Surface topography of the $\mathrm{Ti} / \mathrm{Ti}(\mathrm{C}, \mathrm{N}) / \mathrm{CrN}$ coating deposited onto AZ61 substrate

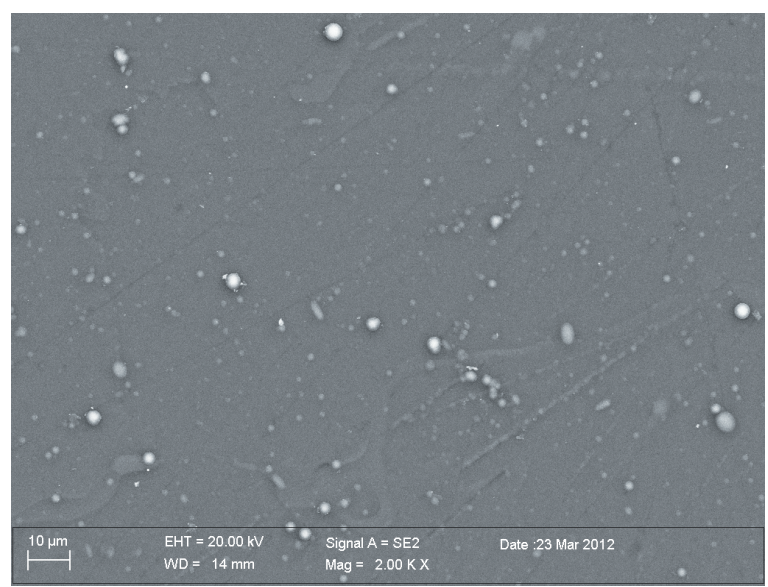

Fig. 16. Surface topography of the Ti/DLC/DLC coating deposited onto AZ61 substrate

alloys substrate, an abrasion test under dry slide friction conditions was carried out by the ball-on- 
disk method. Table 5 presents the friction coefficient and sliding distance results for each type of the investigated substrate.

Under technically dry friction conditions, after the wearing-in period, the friction coefficient recorded for the associations tested is stabilized in the range 0.09 to 0.32 depending on the used substrate and coatings. Rapid changes of the friction coefficient value are caused by the occurrence of pollutants in form of sample counterface spalling products (balls are made from WC), which disturb the measurement of the friction coefficient. Comparing the friction coefficient results with the friction path length, it has been found that the best wear resistance is characteristic for materials coated with DLC carbon. According to the applied load of $5 \mathrm{~N}$, the average friction coefficients for the DLC coatings with the sliding rate of $0.05 \mathrm{~m} / \mathrm{s}$ is in the range of 0.09 to 0.19 , which is several times lower compared to the friction coefficient values of other examined coatings. However, the results of the friction path length for the DLC coatings were at a level exceeding even 11 times the results of the friction path length achieved for the $\mathrm{Ti} / \mathrm{Ti}(\mathrm{C}, \mathrm{N}) / \mathrm{CrN}$ coatings. This is characteristic for DLC coatings as they are composed of poorly ordered graphite, which is probably formed by a friction-assisted phase transformation of the surface layer of the DLC matrix and acts as a lubricant at the surface [18]. Accordingly, the high hardness of DLC together with this transfer layer is responsible for the low friction coefficient of the DLC film in comparison with magnesium alloys coated other investigated coatings. At high sliding speed, the transfer layer is more easily formed due to the accumulation of heat, resulting in a lower friction coefficient.

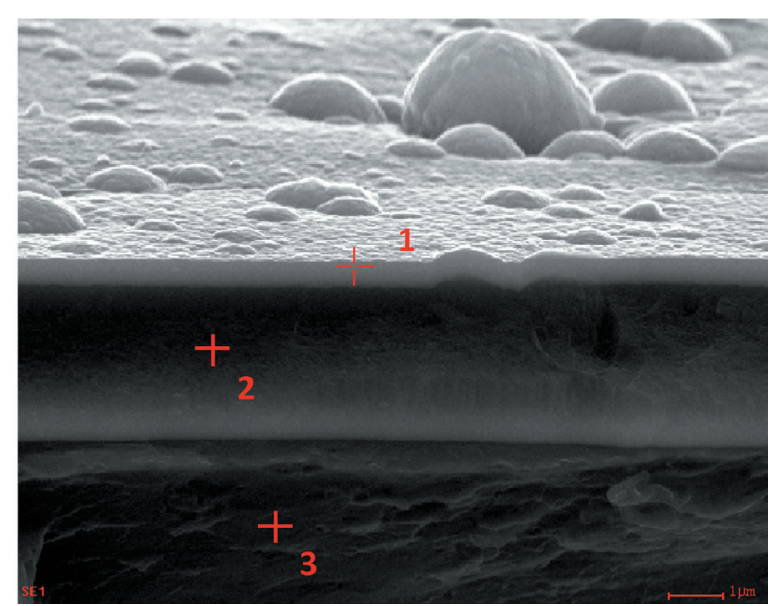

Fig. 17. Cross-section SEM images of the Ti/Ti(C,N)/CrN coating deposited onto the AZ61 substrate
Table 4. The results of quantitative chemical analysis from third 1 , 2, 3 areas of coating Ti/Ti(C,N)/CrN deposited onto substrate from AZ61 alloy marked in Fig. 17

\begin{tabular}{ccc}
\hline \multirow{2}{*}{ Chemical element } & \multicolumn{2}{c}{ The mass and atomic concentration of main } \\
\cline { 2 - 3 } & \multicolumn{2}{c}{ elements [\%] } \\
\cline { 2 - 3 } & \multicolumn{2}{c}{ Analysis 1 (point 1) } \\
\cline { 2 - 3 } $\mathrm{N}$ & 19.64 & 38.24 \\
\hline $\mathrm{Ti}$ & 07.85 & 06.71 \\
\hline $\mathrm{Cr}$ & 72.51 & 55.05 \\
\hline $\mathrm{Matrix}$ & Correction & ZAF \\
\hline & Analysis 2 (point 2) \\
\hline $\mathrm{C}$ & 27.87 & 40.83 \\
\hline $\mathrm{N}$ & 09.12 & 17.86 \\
\hline $\mathrm{Mg}$ & 01.83 & 02.01 \\
\hline $\mathrm{Ti}$ & 52.82 & 35.01 \\
\hline $\mathrm{Cr}$ & 08.36 & 4.29 \\
\hline $\mathrm{Matrix}$ & Correction & ZAF \\
\hline & Analysis 2 (point 3) \\
\hline $\mathrm{Zn}$ & 03.35 & 02.21 \\
\hline $\mathrm{Mg}$ & 85.39 & 87.13 \\
\hline $\mathrm{Al}$ & 11.26 & 10.66 \\
\hline $\mathrm{Matrix}$ & Correction & ZAF
\end{tabular}

Table 5. The characteristics of the investigated coatings

\begin{tabular}{ccccc}
\hline \multicolumn{5}{c}{ Substrate-AZ61 } \\
\hline Coatings & $\begin{array}{c}\text { Critical } \\
\text { load LC1 } \\
{[\mathrm{N}]}\end{array}$ & $\begin{array}{c}\text { Critical } \\
\text { load LC2 } \\
{[\mathrm{N}]}\end{array}$ & $\begin{array}{c}\text { Friction } \\
\text { coefficient }\end{array}$ & $\begin{array}{c}\text { Sliding } \\
\text { disance } \\
{[\mathrm{m}]}\end{array}$ \\
\hline $\mathrm{Ti} / \mathrm{Ti}(\mathrm{C}, \mathrm{N}) / \mathrm{CrN}$ & 3 & 8 & 0.15 to 0.32 & 57 \\
\hline $\mathrm{Ti} / \mathrm{Ti}(\mathrm{C}, \mathrm{N}) /(\mathrm{Ti}, \mathrm{Al}) \mathrm{N}$ & 3 & 10 & 0.17 to 0.22 & 77.7 \\
\hline $\mathrm{Ti} / \mathrm{DLC} / \mathrm{DLC}$ & 6 & 17 & 0.09 to 0.19 & 630 \\
\hline
\end{tabular}

The critical loads LC1 and LC2 were determined in scratch tests. The first critical load LC1 corresponds to the first small jump on the acoustic emission signal, as well as on the friction force curve. The second critical load LC2 is the point at which complete delamination of the coating starts; the first appearance of cracking, chipping, spallation and delamination outside or inside the track with the exposure of the substrate material-the first adhesion-related failure event (Figs. 18b, 19b, 20b). After this point, all the acoustic emission and friction force signals become noisier [14]. The cumulative test results have been listed and compared in Table 3. The highest critical load value $\mathrm{LC} 1=6 \mathrm{~N}$ and $\mathrm{LC} 2=17 \mathrm{~N}$, and that fore the best adhesion of the coating to the substrate was obtained for the Ti/DLC/DLC coating, which is not the best result of coating adhesion to the substrate material, depending mainly on the hardness of the substrate, but for a soft material like magnesium alloy, $17 \mathrm{~N}$ is a plausible result. 


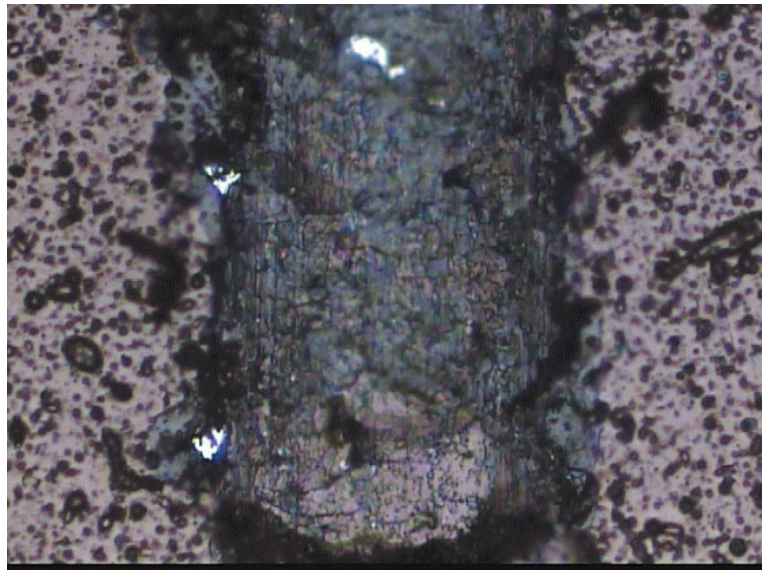

a)

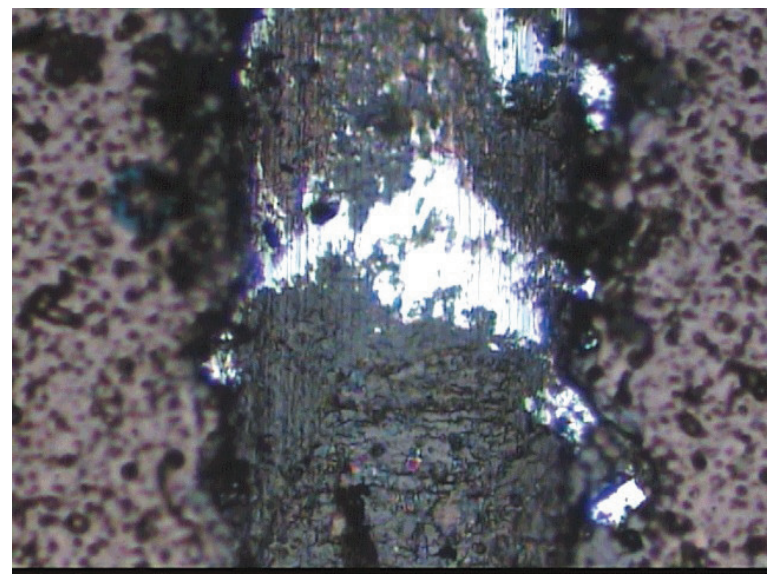

b)

Fig. 18. Scratch failure pictures of the Ti/Ti(C,N)/(Ti,Al)N coating on AZ61 substrate at; a) $L C 1$, and b) $L C 2$

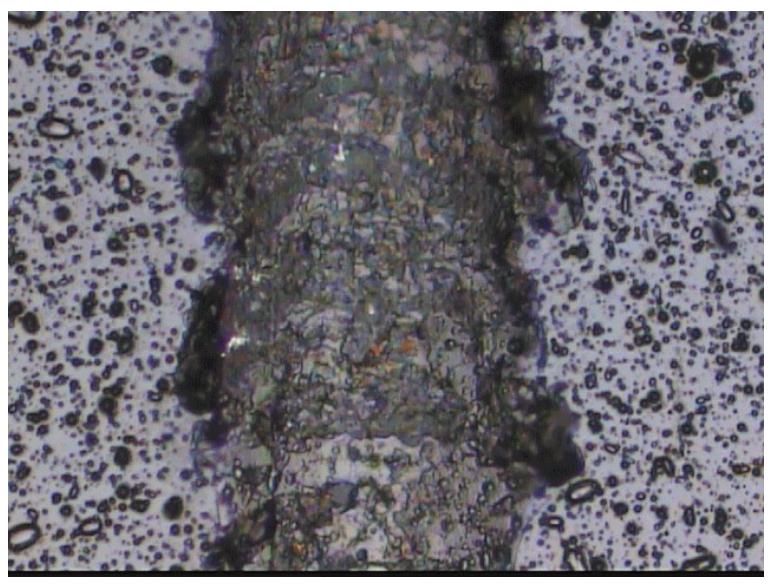

a)

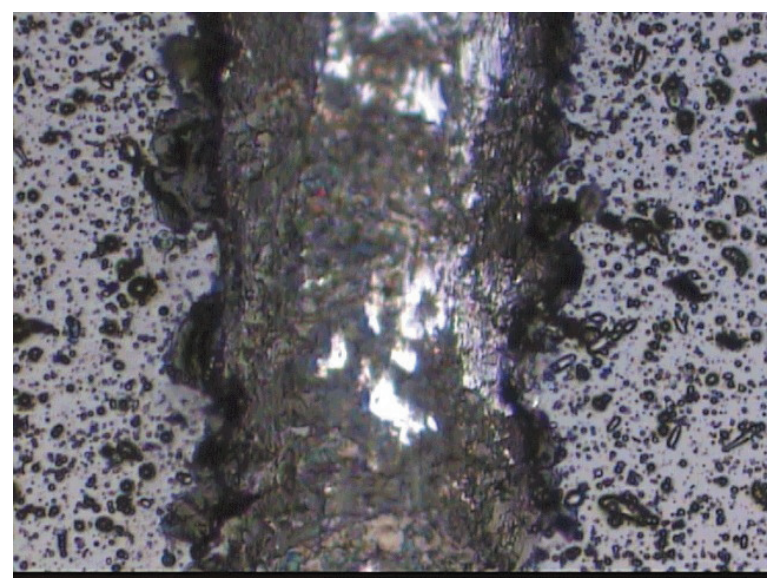

b)

Fig. 19. Scratch failure pictures of the Ti/Ti(C,N)/CrN coating on AZ61 substrate at; a) LC1, and b) LC2

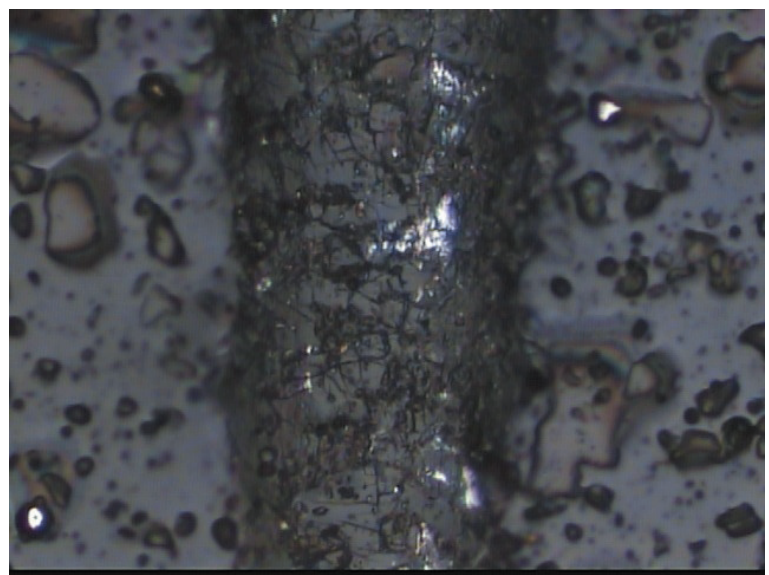

a)

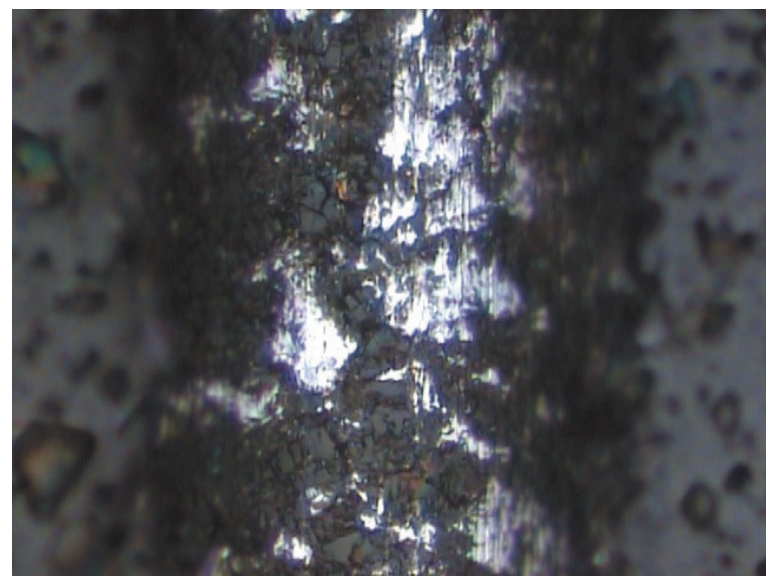

b)

Fig. 20. Scratch failure pictures of the Ti/DLC/DLC coating on AZ61 substrate at; a) LC1, and b) LC2 


\section{SUMMARY}

Due to the character of the investigated material (magnesium alloys) and its relatively low melting point, the whole technological PVD and PACVD processes were performed at temperatures up to $150{ }^{\circ} \mathrm{C}$ for $\mathrm{Ti} / \mathrm{Ti}(\mathrm{C}, \mathrm{N}) / \mathrm{CrN}$ coatings and $\mathrm{Ti} / \mathrm{Ti}(\mathrm{C}, \mathrm{N}) /$ (Ti,Al)N coatings, and up to $180^{\circ} \mathrm{C}$ for Ti/DLC/DLC coating. Investigations carried out using transmission electron microscopy have conformed the $(\mathrm{Ti}, \mathrm{Al}) \mathrm{N}$, $\mathrm{CrN}$ and graphite phases occurred in the surface layer. In order to evaluate the crystallite size of the obtained phases there was used the dark field technique. The size of measured crystallites is in the range of $15 \mathrm{~nm}$. Fracture investigations have confirmed the occurrence of a sharp transition zone between the substrate and the coating. Moreover, it can be observed that the obtained coatings show a tight and compact structure with a lack of visible delamination and defects, are uniformly coated and tightly adhere to the substrate. Comparing the friction coefficient results with the friction path length it has been found that the best wear resistance is characteristic for materials coated with DLC carbon. The scratch tests on coating adhesion reveal the cohesive and adhesive properties of the coatings deposited on the substrate of the AZ61 magnesium alloys. On the basis of the above examinations, it has been found that the critical load of LC2 is between 8 and $17 \mathrm{~N}$. The highest value of the critical load was obtained for the Ti/DLC/DLC coating.

\section{ACKNOWLEDGEMENTS}

Research was financed partially within the framework of the Polish State Committee for Scientific Research Project No. 4688/T02/2009/37 headed by Dr Tomasz Tański.

\section{REFERENCES}

[1] Dobrzański, L.A., Tański, T., Čížek, L. (2006). Influence of $\mathrm{Al}$ addition on microstructure of die casting magnesium alloys. Journal of Achievements in Materials and Manufacturing Engineering, vol. 19, no. 2p. 49-55.

[2] Tański, T., Dobrzański, L.A., Č́́žek, L. (2007). Influence of heat treatment on structure and properties of the cast magnesium alloys. Journal of Advanced Materials Research, vol. 15-17, p. 491-496, DOI:10.4028/www.scientific.net/AMR.15-17.491.

[3] Dobrzański, L.A., Tański, T. (2009). Influence of aluminium content on behaviour of magnesium cast alloys in bentonite sand mould. Solid State Phenomena, vol. 147-149, p. 764-769, DOI:10.4028/www.scientific. net/SSP.147-149.764.

[4] Liang, J., Wang, P., Hu, L.T., Hao, J.C. (2007). Tribological properties of duplex MAO/DLC coatings on magnesium alloy using combined microarc oxidation and filtered cathodic arc deposition. Materials Science and Engineering, vol. A 454-455, p. 164-169, DOI:10.1016/j.msea.2006.12.051.

[5] Zhong, Ch., Liu, F., Wu, Y., Le, J., Liu, L., He, M., Zhu, J., Hu, W. (2012). Protective diffusion coatings on magnesium alloys: A review of recent developments. Journal of Alloys and Compounds, vol. 520, p. 11-21, DOI:10.1016/j.jallcom.2011.12.124.

[6] QiaoU, X., Hou, Y., Wu, Y., Chen, J., (2000). Study on functionally gradient coatings of Ti-Al-N. Surface and Coatings Technology, vol. 131, no. 1-3, p. 462-464, DOI:10.1016/S0257-8972(00)00840-9.

[7] Horst, E.F., Mordike, B.L. (2006). Magnesium Technology: Metallurgy, Design Data, Application. Springer Verlag, Berlin, Heidelberg.

[8] Kulekci, M.K. (2008). Magnesium and its alloys applications in automotive industry. Journal Advanced Manufacturing Technology, vol. 39, no. 9. p. 851-865, DOI:10.1007/s00170-007-1279-2.

[9] Kobold, D., Pepelnjak, T., Gantar, G., Kuzman, K. (2010). Analysis of deformation characteristics of magnesium AZ80 wrought alloy under hot conditions. Strojniški vestnik - Journal of Mechanical Engineering, vol. 56, no. 12, p. 823-832.

[10] Górny, Z., Sobczak, J. (2005). Non-Ferrous Metals Based Novel Materials in Foundry Practice. ZA-PIS, Cracow (in Polish).

[11] Zhao, H., Wang, X.H., Liu, Q.L., Chen, L.J., Liu, Z. (2010). Structure and wear resistance of TiN and TiAlN coatings on AZ91 alloy deposited by multi-arc ion plating. Transactions of Nonferrous Metals Society of China, vol. 20, suppl. 2, p. 679-682, DOI:10.1016/ S1003-6326(10)60561-4.

[12] Altun, H., Sen, S. (2007). The effect of PVD coatings on the wear behaviour of magnesium alloys. Materials Characterization, vol. 58, p. 917-921, DOI:10.1016/j. matchar.2006.09.007.

[13] Gray, J.E., Luan, B. (2002). Protective coatings on magnesium and its alloys-a critical review. Journal of Alloys and Compounds, vol. 336, no. 1-2, p. 88-113, DOI:10.1016/S0925-8388(01)01899-0.

[14] Zeng, L., Yang, S., Zhang, W., Guo, Y., Yan, Ch. (2010). Preparation and characterization of a double-layer coating on magnesium alloy AZ91D. Electrochimica Acta, vol. 55, p. 3376-3383, DOI:10.1016/j. electacta.2010.01.041.

[15] Zou, Y.S., Wu, Y.F., Yang, H., Cang, K., Song, G.H., Li, Z.X., Zhou, K. (2011). The microstructure, mechanical and friction properties of protective diamond like carbon films on magnesium alloy. Applied Surface Science, vol. 258, no. 4, p. 1624-1629, DOI:10.1016/j. apsusc.2011.10.031. 
[16] Hollstein, F., Wiedemann, R., Scholz, J. (2003). Characteristics of PVD-coatings on AZ31HP magnesium alloys. Surface and Coatings Technology, vol. 162 , no. $2-3$, p. 261-268, DOI:10.1016/S02578972(02)00671-0.

[17] Bujak, J., Walkowicz, J., Kusiński, J. (2004). Influence of the nitrogen pressure on the structure and properties of $(\mathrm{Ti}, \mathrm{Al}) \mathrm{N}$ coatings deposited by cathodic vacuum arc PVD process. Surface and Coatings Technology, vol. 180-181, p. 150-157, DOI:10.1016/j. surfcoat.2003.10.058.

[18] Lukaszkowicz, K., Dobrzański, L.A., (2008). Structure and mechanical properties of gradient coatings deposited by PVD technology onto the X40CrMoV5-1 steel substrate. Journal of Materials Science, vol. 43 (2008), p. 3400-3407, DOI:10.1007/s10853-008-2523$3^{\prime \prime}$.

[19] Tański, T., Labisz, K. (2012). Electron microscope investigation of PVD coated aluminium alloy surface layer. Solid State Phenomena, vol. 186, p. 192-197, DOI:10.4028/www.scientific.net/SSP.186.192.

[20] Tański, T. (2012). Investigation of the structure and properties of PVD and PACVD-coated magnesium die cast alloys, Magnesium Alloys. Monteiro, W.A. (ed.), New Features on Magnesium Alloys. InTech, Rijeka, p. 29-52. 